BMJ Open

Sport \&

Exercise

Medicine

\title{
Injuries during the international floorball tournaments from 2012 to 2015
}

\author{
Kati Pasanen, ${ }^{1}$ Merita Bruun, ${ }^{2}$ Tommi Vasankari, ${ }^{3}$ Minna Nurminen, ${ }^{2}$ \\ Walter O Frey ${ }^{4}$
}

To cite: Pasanen K, Bruun $\mathrm{M}$, Vasankari $\mathrm{T}$, et al. Injuries during the international floorball tournaments from 2012 to 2015. BMJ Open Sport Exerc Med 2017;1: e000217. doi:10.1136/ bmjsem-2016-000217

- Prepublication history is available. To view please visit the journal (http://dx.doi.org/ 10.1136/bmjsem-2016000217).

Accepted 9 January 2017

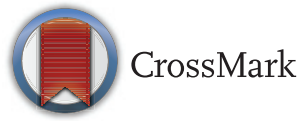

${ }^{1}$ Tampere Research Center of Sports Medicine, UKK Institute for Health Promotion Research, Tampere, Finland ${ }^{2}$ International Floorball Federation, Helsinki, Finland ${ }^{3}$ UKK Institute for Health Promotion Research, Tampere, Finland ${ }^{4}$ Balgrist Movemed, Balgrist University Hospital, Zurich, Switzerland

Correspondence to Dr Kati Pasanen; kati. pasanen@uta.fi

\section{ABSTRACT}

Background: Floorball is a running indoor team sport that has growing popularity worldwide. Some prospective studies have investigated injuries in national floorball leagues, but such studies at the international level are lacking.

Objective: To investigate the incidence and characteristics of injuries during 12 International Floorball Federation (IFF) events.

Methods: All top-level IFF events from 2012 to 2015 were included in the study. The IFF events were divided into the following groups: Men's World Floorball Championships (2012 and 2014), Women's World Floorball Championships (2013 and 2015), Men's Champions Cup (2012, 2013, 2014 and 2015) and Women's Champions Cup (2012, 2013, 2014 and 2015). The team medical personnel prospectively recorded the injuries that occurred in games and practices. The time of exposure was calculated for entire teams based on the IFF statistics.

Results: Sixty-eight injuries were registered among 67 players. Sixty-five of the injuries occurred in games, resulting in an injury incidence of 21.24 per 1000 game hours $(95 \% \mathrm{Cl} 16.13$ to 26.35$)$. There was no significant difference in the incidence of game injuries between females and males (incidence rate ratio 0.68 , $95 \% \mathrm{Cl} 0.41$ to 1.11). The ankle was the most common site of injury (24\%), followed by the head $(18 \%)$ and the knee $(18 \%)$. Almost half of the injuries $(46 \%)$ involved joints or ligaments.

Conclusions: Risk of injury during IFF tournaments was lower than in many other team sports at the highest level of play. Preventive actions should focus on acute ankle and knee injuries as well as head and face injuries.

\section{INTRODUCTION}

Floorball is a running indoor team sports that has spread rapidly throughout the world. The game is relatively young, as the International Floorball Federation (IFF) was founded in 1986 by the national floorball associations of Sweden, Finland and Switzerland. ${ }^{1}$ Today, the IFF has over 60 member associations and about 310000 licensed players. ${ }^{1}$ The Men's World Floorball Championships (WFC) is played every even year in December, and Women's WFC is played every odd year in December.

\section{Key messages \\ What are the new findings? \\ - The majority of injuries in international floorbal tournaments affected the lower extremity, and almost half of the injuries involved joints or ligaments. \\ - Ankle and knee ligament injuries were the most common injury types. \\ - Distribution of head and face injuries was notable, even though the severity of the injuries was minor.}

How might it impact clinical practice in the near future?

- Preventive measures should focus on ankle and knee ligament injuries, and the rate of severe knee ligament injuries, including $\mathrm{ACL}$ ruptures, should be closely followed.

- Injuries to the head and face should be taken to the closer consideration to justify possible rule changes.

The importance of using protective goggles to avoid eye injuries should be further stressed.

Another international tournament is the Champions Cup (CC), which is the championship tournament for the European topranked club teams. The CC is played every year in October with six teams for both women and men. In 2011, floorball became a fully recognised sport of the IOC. ${ }^{1}$

Floorball is played on a $40 \times 20 \mathrm{~m}$ court surrounded by a $0.5 \mathrm{~m}$ high plastic rink. The floorball teams consist up to 20 players, and six of them are on the court at the same time: five field players and a goalkeeper. The movement patterns of the field players include handling a stick and the ball during interval running, accelerations, sudden stops and changes of moving direction. Goalkeepers play mostly on their knees, and they protect the goal with their hands, legs and body. The standard game length is $3 \times 20 \mathrm{~min}$, and substitutions are permitted any time during the game. Aggressive body contacts, tackling and 


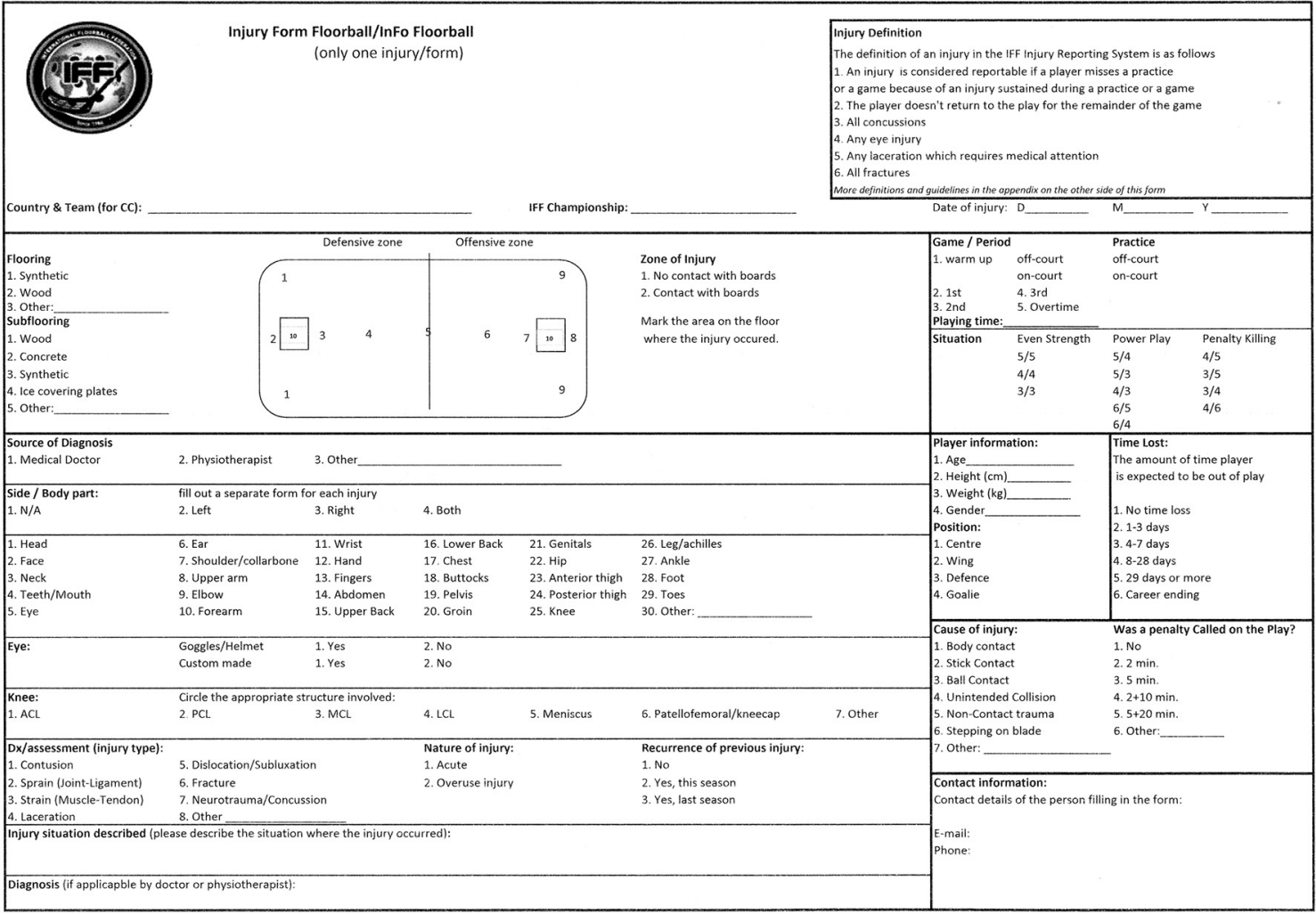

Figure 1 Injury form of the International Floorball Federation.

robust play are not allowed. However, due to highintensity and multi-directional movements on a relatively small playing area, accidental contacts with other players, boards and goals appear frequently.

Previous studies on floorball injuries have focused on the national level..$^{2-15}$ These investigations have shown that most of the acute injuries in floorball affect the ankle and knee, ${ }^{2-7}$ whereas overuse injuries involve most commonly leg/calf, knee and lower back. $^{5}{ }^{8-10}$ Severe knee ligament injuries, such as ruptures of the ACL, have proven to be a concern in floorball national leagues, specifically among female players..$^{5} 7^{11} \mathrm{In}$ addition, the risk of eye injuries is high in floorball. ${ }^{12-14}$

The IFF injury surveillance system was established in 2012 to follow-up the rate and type of injuries in the major IFF events. Little is known about floorball injuries among international players, and therefore, the purpose of the present study was to investigate the incidence and characteristics of injuries during men's and women's top-level IFF events from 2012 to 2015.

\section{METHODS}

\section{Study design and participants}

With the permission of the IFF, the data of injuries and exposure from 12 IFF events (two WFC tournaments and four CC tournaments for both men and women) from 2012 to 2015 were analysed. A total of 253 games were played by 112 teams. All players selected to the participating teams were included in the study. The injury data were collected prospectively and anonymously.

\section{Injury and exposure data collection}

The team officials were informed about the injury data collection in the information letters sent to each team and also at the technical meetings prior to each tournament. An injury was defined as any injury that occurred during a floorball game or practice (figure 1). The team medical personnel were requested to report all injuries during games and practices throughout the events by using a structured one-page injury form (figure 1). The form was adapted from the form of the International Ice Hockey Federation. ${ }^{16}$ Diagnosing was based on the findings of physical examination performed instantly after an injury had occurred. In addition, the team medical personnel were required to inform the IFF and one of the researchers (MB) if the diagnosis or other information of the injury changed in the future examinations (eg, MRI).

In order to guarantee that all the injury data were collected during the events, the teams were not allowed to change an injured player to another player before returning the filled-in injury form. Also the IFF jury members, who were observing each game during an event, had the task to report to the IFF officials if they observed an injury during a game. When the IFF jury members reported an injury to the IFF officials, this was then recorded in the daily report with the name of the team with an injury. Based on this, the IFF officers 
could make follow-up and check that all the injury forms had been returned. Once an injury form was returned, this was also noted in the daily report.

The injury data were processed anonymously; in other words, the personal information comprised nothing more than the athlete's team, playing position, age, weight, height and sex. The contact information of the team medical personnel who was responsible for completing the injury form was collected in case there was a need to check some information later on. One of the IFF officials who attended the events was always given the responsibility for making sure that all injuries were accurately reported. The time of exposure to games and practices was calculated for entire teams, and it was based on the tournament statistics that were systematically collected by the IFF. The total number of games played was recorded. The game exposure time was calculated as follows: each game lasts $60 \mathrm{~min}$ of actual play, and there are always six players from each team on the court (a goalkeeper and five field players). Accordingly, the total exposure is 12 hours per game (6 hours per team). In addition, the IFF data included information of played overtime periods. The overtime in floorball games follow the golden goal rule, meaning that the overtime ends immediately when one of the teams scores. The length of played overtime was added to the regular playing time with the same principles as described previously. The reduced numbers of players on the court due to penalties were not taken into account.

The IFF organised a scheduled practice session ( 1 hour) on court once a day for each participating team. We calculated the training exposure for each team by multiplying the number of team training sessions with the number of team players in an event ( $\mathrm{N}$ of sessions $\mathrm{x} \mathrm{N}$ of players). Moreover, warm-up sessions prior to the games were added to the training exposure. The teams performed $30 \mathrm{~min}$ scheduled warm-ups before the matches. The warm-up exposure for a team was calculated like training exposure by multiplying the number of games with the number of players in a squad. Other practices performed outside the IFF arrangements were not included in the exposure data. The details of each participating team ( $\mathrm{N}$ of players, $\mathrm{N}$ of games and team practices) and players' age were received from the database of the IFF. All the details of exposure and the reported injuries were recorded by two researchers ( $\mathrm{MB}$ and $\mathrm{MN})$.

\section{Statistical analysis}

The data were analysed using SPSS (SPSS for Windows, V.22, Chicago, Illinois, USA) and OpenEpi (V.3.01). ${ }^{17}$ Frequency tables were used to describe categorical variables. The injury incidence was expressed as the number of injuries per 1000 hours of exposure. Injury incidence was calculated separately for games and practices, and for males and females. The Mid-P Exact test was used to compare incidence rates between subgroups. The injury incidences and incidence rate ratios (IRRs) were expressed with 95\% CI.

\section{RESULTS}

\section{Exposure and incidence of injuries}

Altogether, 1226 team training sessions (19 054 hours), comprising scheduled team practices and game warmups, and 253 games (3 060 hours) were followed during the 12 international events (table 1). In total, 68 injuries were registered among 67 players. All except one of the injuries were acute traumas. Sixtyfive injuries occurred in games, resulting in an injury incidence of 21.24 per 1000 game hours (95\% CI 16.13 to 26.35). Rates of injury by type of event and exposure are presented in table 1 . There was no significant difference in injury rates between males and females (table 2).

\section{Injury sites and types}

Anatomical location and type of injuries are presented in table 3. Most of the injuries (64\%) involved the lower limb. Almost half of the injuries affected joints or ligaments (46\%). Ankle joint sprain was the most common type of injury (21\%). Other joint/ligament injuries involved the knee (18\%) and the shoulder $(3 \%)$. Contusions affected the head or face $(9 \%)$, the lower extremity $(9 \%)$, the trunk $(6 \%)$ and the upper extremity $(3 \%)$. Contusions of head/face included two eye injuries. The muscle or tendon injuries involved most frequently the leg/Achilles $(6 \%)$ and the thigh $(4 \%)$. All five lacerations were located on the head/face, and they were caused by a stick. Moreover, two fractures (rib and foot) and one concussion occurred during the follow-up. Only one overuse injury, an Achilles tendon pain in a female player, was reported during the study.

Eight injuries (12\%) were reported to be recurrent injuries. In six cases, the prior injury had occurred during the ongoing season (but not in the concerned tournament): three ankle sprains; a medial collateral ligament (MCL) injury of the knee; a shoulder dislocation; and a hamstring strain. In two cases, the prior injury had occurred during the previous season: an Achilles tendon pain and an MCL injury.

\section{Place and time of injury occurrence}

The game injuries $(n=65)$ occurred near the corners (45\%), around the midfield (31\%), outside but near the goal area $(17 \%)$ and in the goal area $(2 \%)$. In addition, seven injury situations included contacts with the boards. In four cases $(6 \%)$, the area where the injury occurred was unclear (missing data). Most of the game injuries took place during the second period (35\%), followed by third period (32\%), and overtime (29\%). Wing players suffered $42 \%$ of game injuries, defensive players suffered $37 \%$ of game injuries, centre players suffered $18 \%$ of game injuries and goalkeepers 


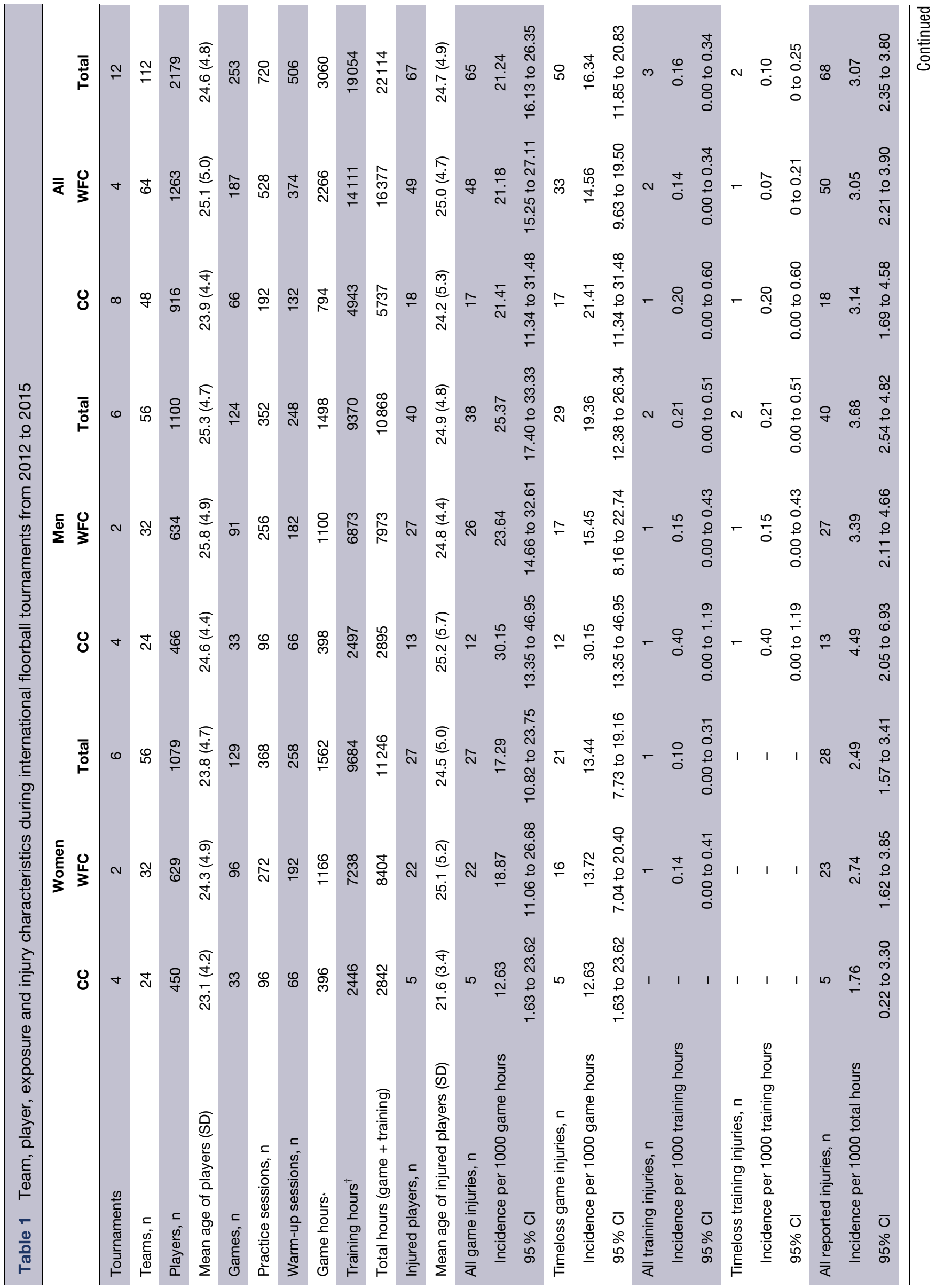


suffered $3 \%$ of game injuries. The majority of the game injuries $(88 \%)$ occurred when both teams were playing full strength. Three minor injuries occurred during training: two ankle joint/ligament injuries (minimal and moderate injury) and an overuse injury of an Achilles tendon (slight injury).

\section{Injury circumstances}

Thirty-two injuries $(47 \%)$ were reported as the result of body contact, whereas 20 injuries (29\%) had occurred in non-contact circumstances. Nine injuries were caused by a stick (hit or trip). The distribution of the three most common injury locations by cause of injury is presented in table 4. All in all, the number of head/ face injuries was relatively high (18\%), and two of them affected the eye. One eye injury was caused by body contact and another by the ball. Only one of the players with head/face injury appeared to wear protective eyewear when the injury occurred. Penalties were assessed in five body contact situations that resulted in an injury, but none of the head/face injuries caused by a stick ended in penalties.

\section{Injury severity}

The incidence of time-loss injuries in games was 16.34 per 1000 hours (95\% CI 11.85 to 20.83) (table 1). More than half $(56 \%)$ of injuries were slight to mild (table 5). Sixteen of the reported injuries did not cause time-loss from floorball training or playing, including eight injuries to the head/face (five lacerations, two eye injuries and one teeth/mouth injury), four contusions (lower back, finger, hand and foot), two ankle joint/ligament injuries, a hamstring strain and an overuse injury of an Achilles tendon.

However, the percentage distribution of severe injuries was notable (19\% of all injuries). Severe injuries included eight knee ligament injuries (6 in females; 2 in males), two ankle ligament injuries, a shoulder dislocation, and two fractures (rib and foot). All severe injuries occurred in games, giving an incidence of 4.25 severe injuries per 1000 game hours (95\% CI 1.94 to 6.55). The incidence of severe injuries did not differ between females and males (table 2). Five ACL injuries occurred in games, and four of them occurred in females.

\section{DISCUSSION}

This is the first study on floorball injuries in international tournaments. The majority of the injuries occurred during games and had a sudden onset. The incidence of all reported injuries in games was 21.24 (95\% CI 16.13 to 26.35 ) per 1000 hours, and the incidence of time-loss injuries was 16.34 (95\% CI 11.85 to 20.83). No significant differences were found in injury rates between females and males.

The incidence of game injuries in the current study was substantially lower than reported in international 
Table 2 Number and incidence of game injuries and incidence rate ratio for female and male players

\begin{tabular}{|c|c|c|c|c|c|}
\hline & \multicolumn{2}{|r|}{ Women } & \multicolumn{2}{|r|}{ Men } & \multirow[b]{2}{*}{ IRR (95\% Cl) } \\
\hline & $\mathbf{n}$ & Incidence $(95 \% \mathrm{Cl})$ & $\mathbf{n}$ & Incidence $(95 \% \mathrm{Cl})$ & \\
\hline All game injuries & 27 & 17.29 (10.82 to 23.75$)$ & 38 & 25.37 (17.40 to 33.33$)$ & $0.68(0.41$ to 1.11$)$ \\
\hline Time-loss game injuries & 21 & 13.44 (7.73 to 19.16$)$ & 29 & 19.36 (12.38 to 26.34$)$ & $0.69(0.39$ to 1.21$)$ \\
\hline Severe game injuries & 9 & 5.76 (2.01 to 9.56$)$ & 4 & 2.67 (0.06 to 5.28$)$ & $2.16(0.67$ to 8.06$)$ \\
\hline Ankle injuries & 6 & 3.84 (0.77 to 6.91$)$ & 8 & 5.34 (1.65 to 9.03$)$ & 0.71 (0.23 to 2.12$)$ \\
\hline Head/face injuries & 4 & 2.56 (0.05 to 5.07$)$ & 8 & 5.34 (1.65 to 9.03$)$ & $0.48(0.13$ to 1.59$)$ \\
\hline Knee injuries & 7 & 4.48 (1.17 to 7.79$)$ & 5 & $3.34(0.42$ to 6.26$)$ & 1.34 (0.41 to 4.63$)$ \\
\hline ACL injuries & 4 & $2.56(0.05$ to 5.7$)$ & 1 & $0.67(0.00$ to 1.98$)$ & 3.84 (0.48 to 94.92$)$ \\
\hline
\end{tabular}

IRR, incidence rate ratio.

futsal (195.6 per 1000 hours in men) ${ }^{18}$ handball (104.5 in men), ${ }^{19}$ football (40.1 in men), ${ }^{20}$ ice hockey (52.1 in men; 20.0 in women) ${ }^{1621}$ and field hockey (48.3 in men; 29.1 in women), ${ }^{22}$ but somewhat higher than found in volleyball (11.9 in men; 12.2 in women). ${ }^{23}$

Table 3 Anatomical location and type of injuries $(n=68)$ by sex, given as number of injuries

\begin{tabular}{lccc}
\hline & Women & Men & Total \\
\hline All injuries & 28 & 40 & 68
\end{tabular}

Anatomical location

\begin{tabular}{|c|c|c|c|}
\hline Ankle & 6 & 10 & 16 \\
\hline Head/face & 4 & 8 & 12 \\
\hline Knee & 7 & 5 & 12 \\
\hline Thigh & 3 & 3 & 6 \\
\hline Lower leg/Achilles & 2 & 3 & 5 \\
\hline Foot & 1 & 3 & 4 \\
\hline Abdomen/chest & 2 & 1 & 3 \\
\hline Lower back/pelvis & 1 & 2 & 3 \\
\hline Neck & - & 2 & 2 \\
\hline Shoulder/clavicula & - & 2 & 2 \\
\hline Hand/finger & 2 & - & 2 \\
\hline Hip & - & 1 & 1 \\
\hline \multicolumn{4}{|l|}{ Type of injury } \\
\hline Joint/ligament & 13 & 18 & 31 \\
\hline Contusion & 6 & 12 & 18 \\
\hline Muscle/tendon & 4 & 7 & 11 \\
\hline Laceration & 2 & 3 & 5 \\
\hline Fracture & 2 & - & 2 \\
\hline Concussion & 1 & - & 1 \\
\hline
\end{tabular}

Injury sites and types in this study were consistent with the findings from previous studies from the national floorball league level, indicating that the most frequently injured body parts are the ankle and knee, and the most common injury type is joint sprain. ${ }^{2-7}$ Surprisingly, the proportion of head/face injuries in this study was notable (18\%), but fortunately most of them were minor injuries. However, the number of head/face injuries should be taken into consideration, as they were mostly caused by a stick. A hit by a stick or the ball can cause more severe injuries such as eye injuries. ${ }^{12-14}$ Interestingly, only one of the players who suffered head/face injury wore goggles. Moreover, none of the five face lacerations that were caused by a stick resulted in a penalty.

Only one overuse injury was reported in this study. The true number of overuse injuries is probably greater than what we captured, as athletes often continue playing and training despite having a musculoskeletal complaint. Data recording was only done on injuries reported to the medical personnel of each team. Thus, it is possible that minor and self-treated injuries may not have been recorded at all. A different approach is needed to collect more accurate information of overuse injuries and minor acute injuries. Clarsen $e t a l^{8} 24$ have developed a new method for registering data of non-time-loss injuries, and this could be an applicable procedure for data collection during international tournaments as well.

The majority of injuries occurred in games, and nearly half of the game injuries took place in the court corners. Body contacts and frequent direction changes occur often in corners when the defensive player tries to win the ball from the offensive player. Not surprisingly, the injury risk was lowest during the first period and clearly higher during the following periods. This might be a consequence of fatigue or more intensive play during the latter periods. It is also notable that the overall physical and mental loading is extremely high in international tournaments with matches almost every day. The recovery time is often insufficient and 
Table 4 Reported cause of ankle, knee and head/face injuries

\begin{tabular}{lccc}
\hline & Ankle & Knee & Head/face \\
\hline Body contact & 7 & 5 & 6 \\
Stick contact & 1 & - & 5 \\
Ball contact & - & - & 1 \\
Unintended collision & 1 & 2 & - \\
Non-contact trauma & 6 & 4 & - \\
NA (missing data) & 1 & 1 & - \\
Total & 16 & 12 & 12 \\
\hline
\end{tabular}

can result in decreased neuromuscular performance and an increased injury risk.

We found that $66 \%$ of all injuries occurred in contact situations, such as body contact, stick contact or collision, and 29\% were reported as non-contact trauma. However, we did not investigate whether an injury resulted from a direct or indirect contact situation. According to Olsen and co-workers, injuries should be defined as contact (direct contact tot the injured body region), indirect contact (contact with other body parts) and non-contact injuries. ${ }^{25}$ This knowledge on the injury mechanism is essential for choosing effective prevention methods. ${ }^{26}$

Fortunately, more than half of injuries were minor (expected time loss from training and playing $\leq 1$ week). Twenty-four percent of the injuries did not cause absence from sport at all, and the remaining $76 \%$ resulted in time-loss of 1 or more days. However, the distribution of severe injuries was noteworthy (19\%). Furthermore, female players suffered more severe injuries, especially severe knee injuries, than male players. Previous studies on sex differences in the risk of injury have revealed that female athletes are more prone to severe knee injuries. ${ }^{27} 28$ However, the total number of severe knee injuries in this study was low, thus reading the results should be done cautiously. We did not find differences in the risk of injuries between sexes. More data is needed to analyse differences between subgroups.

Our study has several strengths, including a prospective design, exact team-based exposure time collection and high accuracy of injury reporting. However, this study has also some limitations that must be taken into consideration. Even though the researchers requested the medical personnel to inform if the details of certain injury changed, the injured players might not have informed the team medical personnel about the medical examinations performed at home after the tournament. Hence, some details regarding severity and diagnosis may have changed in later examinations. In addition, only one overuse injury was reported, albeit the loading is very high during the
Table 5 Expected time loss from training and playing due to injury $(n=68)$ by sex, given as number of injuries

\begin{tabular}{lccc}
\hline & Women & Men & Total \\
\hline Slight (no absence) & 7 & 9 & 16 \\
Minimal (1-3 days) & 7 & 10 & 17 \\
Mild (4-7 days) & 1 & 4 & 5 \\
Moderate (8-28 days) & 4 & 13 & 17 \\
Severe ( $\geq 29$ days) & 9 & 4 & 13 \\
Total & 28 & 40 & 68 \\
\hline
\end{tabular}

tournaments. This may indicate that we were not able to capture all musculoskeletal complaints, specifically minor and self-treated overuse and acute injuries. It is also possible that the players do not want to report minor injuries, as injured player may have less playing time.

Moreover, we did not take into account the number and duration of played power plays and penalty killings, which may have affected slightly on the total game exposure time a bit. In addition, the exposure time on scheduled team practices during the events was not based on explicit team and player monitoring, which can be seen as a weakness. The training exposure was calculated based on the presumption that all team players performed each scheduled training session. In fact, the teams might not perform all the scheduled training sessions, or their performed training sessions might have been shorter than scheduled, or only part of the team players might took part in a training session. After all, we may have overestimated both game and training exposures, and thus the injury incidences might be underestimated. However, the number of training injuries was very low $(n=3)$, hence this should not have a significant influence on the study results. Ultimately, the results of the current study must be considered as the minimum estimate of injury rates.

\section{Summary}

This is the first epidemiological study exploring injuries in major IFF events. The injury risk among international-level floorball players is lower than in many other team ball sports at the highest level of play. Preventive actions in international floorball should focus on acute ankle and knee injuries as well as head and face injuries.

Acknowledgements The authors would like to thank the International Floorball Federation and the Finnish Ministry of Education and Culture for financial support. The authors greatly acknowledge the cooperation of team physicians, physiotherapists and other medical personnel who collected the data for this project. The authors would like to thank the International Floorball Federation's Medical Committee for all practical support. 
Contributors MB and WOF planned the data collection. MB was responsible for data recording with the help of MN KP was responsible for literature search and data analysis. KP wrote the first draft of the paper. All authors contributed to the final paper. KP is responsible for overall content as the guarantor.

Funding This study was financially supported by the International Floorball Federation and the Finnish Ministry of Education and Culture.

Competing interests None declared.

Provenance and peer review Not commissioned; externally peer reviewed.

Open Access This is an Open Access article distributed in accordance with the Creative Commons Attribution Non Commercial (CC BY-NC 4.0) license, which permits others to distribute, remix, adapt, build upon this work noncommercially, and license their derivative works on different terms, provided the original work is properly cited and the use is non-commercial. See: http:// creativecommons.org/licenses/by-nc/4.0/

(c) Article author(s) (or their employer(s) unless otherwise stated in the text of the article) 2017. All rights reserved. No commercial use is permitted unless otherwise expressly granted.

\section{REFERENCES}

1. Bruun $\mathrm{M}$, Halonen $\mathrm{V}$, Kratz $\mathrm{S}$, et al. This is floorball $-25^{\text {th }}$ anniversary. International Floorball Federation 2011 https://issuu.com/iff floorball/ docs/this_is_floorball_2011_issuu (accessed 28 Jun 2016).

2. Löfgren $\mathrm{O}$, Andersson N, Björnstig U, et al. Incidence, nature and causes of floorball injuries. Scandinavian Journal of Medicine \& Science in Sports 1994;4:211-4.

3. Wikström J, Andersson C. A prospective study of injuries in licensed floorball players. Scand J Med Sci Sports 1997;7:38-42.

4. Snellman K, Parkkari J, Kannus $\mathrm{P}$, et al. Sports injuries in floorball: a prospective one-year follow-up study. Int J Sports Med 2001;22:531-6.

5. Pasanen K, Parkkari J, Kannus $P$, et al. Injury risk in female floorball: a prospective one-season follow-up. Scand J Med Sci Sports 2008;18:49-54.

6. Pasanen K, Parkkari J, Rossi L, et al. Artificial playing surface increases the injury risk in pivoting indoor sports: a prospective oneseason follow-up study in finnish female floorball. Br J Sports Med 2008;42:194-7.

7. Tranaeus U, Götesson E, Werner S. Injury profile in swedish elite floorball: a prospective cohort study of 12 teams. Sports Health 2016;8:224-9.

8. Clarsen B, Bahr R, Heymans MW, et al. The prevalence and impact of overuse injuries in five norwegian sports: Application of a new surveillance method. Scand J Med Sci Sports 2015;25:323-30.

9. Pasanen K, Rossi M, Parkkari J, et al. Low back pain in young basketball and floorball players. Clin J Sport Med 2016;26:376-80.

10. Leppänen M, Pasanen K, Kujala UM, et al. Overuse injuries in youth basketball and floorball. Open Access J Sports Med 2015;6:173-9.
11. Leppänen M, Pasanen K, Kujala UM, et al. Stiff landings are associated with increased ACL injury risk in young female basketball and floorball players. Am J Sports Med 2017;45:386-93.

12. Leivo T, Puusaari I, Mäkitie T. Sports-related eye injuries: floorball endangers the eyes of young players. Scand J Med Sci Sports 2007; 17:556-63.

13. Maxén M, Kühl S, Krastl G, et al. Eye injuries and orofacial traumas in floorball-a survey in Switzerland and Sweden. Dent Traumatol 2011;27:95-101.

14. Bro T, Ghosh F. Floorball-related eye injuries: The impact of protective eyewear. Scand J Med Sci Sports 2016:n/a.

15. Pasanen K, Parkkari J, Pasanen M, et al. Neuromuscular training and the risk of leg injuries in female floorball players: cluster randomised controlled study. BMJ 2008;337:a295.

16. Tuominen M, Stuart MJ, Aubry M, et al. Injuries in men's international ice hockey: a 7-year study of the International Ice Hockey Federation Adult World Championship Tournaments and Olympic Winter Games. Br J Sports Med 2015;49:30-6.

17. Dean AG, Sullivan KM, Soe MM. OpenEpi: Open Source Epidemiologic Statistics for Public Health. version 3.01, updated 2013/04/06. www.OpenEpi.com. (accessed 08 Dec 2016).

18. Junge A, Dvorak J. Injury risk of playing football in futsal world cups. Br J Sports Med 2010;44:1089-92.

19. Bere T, Alonso JM, Wangensteen A, et al. Injury and illness surveillance during the $24^{\text {th }}$ men's Handball World Championship 2015 in Qatar. Br J Sports Med 2015;49:1151-6.

20. Dvorak J, Junge A, Derman W, et al. Injuries and illnesses of football players during the 2010 FIFA world cup. Br J Sports Med 2011;45:626-30.

21. Tuominen M, Stuart MJ, Aubry M, et al. Injuries in women's international ice hockey: an 8-year study of the World Championship tournaments and Olympic Winter Games. $\mathrm{Br} J$ Sports Med 2016;50:1406-12.

22. Theilen TM, Mueller Eising W, Wefers Bettink $P$, et al. Injury data of major international field hockey tournaments. Br J Sports Med 2016;50:657-60.

23. Bere T, Kruczynski J, Veintimilla N, et al. Injury risk is low among world-class volleyball players: 4-year data from the FIVB Injury Surveillance System. Br J Sports Med 2015;49:1132-7.

24. Clarsen B, Myklebust G, Bahr R. Development and validation of new method for the registration of overuse injuries in sports injury epidemiology: the Oslo Sports Trauma Research Centre (OSTRC) overuse injury questionnaire. Br J Sports Med 2013;47:495-502.

25. Olsen OE, Myklebust G, Engebretsen L, et al. Injury mechanisms for anterior cruciate ligament injuries in team handball: a systematic video analysis. Am J Sports Med 2004;32:1002-12.

26. Bahr R, Krosshaug T. Understanding injury mechanisms: a key component of preventing injuries in sport. $\mathrm{Br} J$ Sports Med 2005;39:324-9.

27. Agel J, Arendt EA, Bershadsky B. Anterior cruciate ligament injury in national collegiate athletic association basketball and soccer: a 13year review. Am J Sports Med 2005;33:524-31.

28. Ingram JG, Fields SK, Yard EE, et al. Epidemiology of knee injuries among boys and girls in US high school athletics. Am J Sports Med 2008;36:1116-22. 